FERNANDO CALIX COELHO DA COSTA

\title{
O DIRIGENTE DE EMPRESA COMO GARANTE DE PROTEÇÃO
}

\author{
Dissertação de Mestrado
}

Orientadora: Professora Titular Ana Elisa Liberatore Silva Bechara

UNIVERSIDADE DE SÃO PAULO

FACULDADE DE DIREITO

São Paulo-SP

2018 


\section{FERNANDO CALIX COELHO DA COSTA}

\section{O DIRIGENTE DE EMPRESA COMO GARANTE DE PROTEÇÃO}

Dissertação apresentada à Banca Examinadora do Programa de Pós-graduação em Direito, da Faculdade de Direito da Universidade de São Paulo, como exigência parcial para obtenção do Título de Mestre em Direito, na área de concentração Direito Penal, Medicina Forense e Criminologia, sob orientação da Professora Titular Ana Elisa Liberatore Silva Bechara.

UNIVERSIDADE DE SÃO PAULO

FACULDADE DE DIREITO

São Paulo-SP

2018 
Autorizo a reprodução e divulgação total ou parcial deste trabalho, por qualquer meio convencional ou eletrônico, para fins de estudo e pesquisa, desde que citada a fonte.

Catalogação da Publicação

Serviço de Biblioteca e Documentação

Faculdade de Direito da Universidade de São Paulo

Costa, Fernando Calix Coelho da.

O dirigente de empresa como garante de proteção/ Fernando Calix Coelho da Costa; orientadora Ana Elisa Liberatore Silva Bechara -- São Paulo, 2018. Páginas 192.

Dissertação (Mestrado - Programa de Pós-Graduação em Direito Penal, Medicina Forense e Criminologia) - Faculdade de Direito, Universidade de São Paulo, 2018.

1. criminalidade econômica. 2. responsabilidade penal dos dirigentes. 3. omissão imprópria. 4. garante de proteção. 5. patrimônio da empresa. 6. saúde do trabalhador. I. Bechara, Ana Elisa Liberatore Silva, orient. II. Título. 


\section{FERNANDO CALIX COELHO DA COSTA}

\section{O DIRIGENTE DE EMPRESA COMO GARANTE DE PROTEÇÃO}

Dissertação apresentada à Banca Examinadora do Programa de Pós-graduação em Direito, da Faculdade de Direito da Universidade de São Paulo, como exigência parcial para obtenção do Título de Mestre em Direito, na área de concentração Direito Penal, Medicina Forense e Criminologia, sob orientação da Professora Titular Dra. Ana Elisa Liberatore Silva Bechara.

\section{BANCA EXAMINADORA}

Presidente:

Professora Titular Dra. Ana Elisa Liberatore Silva Bechara

$1^{\circ}$ Examinador (a): INSTITUIÇÃO

Julgamento: ASSINATURA

$2^{\circ}$ Examinador (a): INSTITUIÇÃO Julgamento: ASSINATURA

$3^{\circ}$ Examinador (a): INSTITUIÇÃO Julgamento: ASSINATURA 
Aos meus pais Rosangela e Antônio (in memorian), pelo amor e apoio incondicionais e por terem renunciado às próprias vidas pela criação dos seus três filhos. 


\section{AGRADECIMENTOS}

Haja vista o objeto a que se dedicou o presente estudo, não poderia me omitir quanto ao dever moral, com fundamento material no reconhecimento, e deixar de reconhecer e agradecer às pessoas que tanto contribuíram para a realização deste trabalho.

A despeito de Umberto Eco afirmar que não se deveria citar nos agradecimentos a orientadora da dissertação, pois, para ele, seria um mero cumprimento de uma obrigação, seria uma omissão das mais graves deixar de agradecer à professora Ana Elisa Liberatore Silva Bechara.

Isso porque ela foi muito além de orientar, de modo que essa dissertação não teria sido produzida sem o seu infatigável alento e fundamental orientação a este mestrando, que já superam os 9 anos (desde o início da graduação). Obrigado, também, por despertar em mim o amor pela docência e pelas valiosas aulas na graduação e no mestrado.

Ao professor Pierpaolo Cruz Bottini, agradeço pelas imprescindíveis orientações no meu exame de qualificação. Ao professor, mestre e orientador de todos nós, Luis Greco, agradeço pelo amável recebimento na Alemanha para a minha estada temporária para pesquisa. À Heloísa Estellita, agradeço as orientações acadêmica e de vida e, principalmente, pela amizade.

Agradeço à minha tia Regina Calix, pessoa com poder de superação e abnegação indescritíveis, a qual tomei como mãe em muitos momentos da minha vida e às minhas queridas irmãs Roberta Calix e Eduarda Calix, pela maneira particular de cada uma delas de me demonstrar carinho, ternura e apoio. Ainda no âmbito familiar, agradeço o apoio do primo Álvaro Kalix, cujo altruísmo ainda me é inexplicável.

Agradeço à Fernanda Douat pela mais simples das razões: não há outra pessoa que teria a mesma paciência, dedicação e disposição para caminhar ao meu lado nesse longo caminho.

Aos amigos que as arcadas da Faculdade de Direito do Largo de São Francisco me deram, agradeço a amizade e companheirismo nos longos anos da graduação e, agora, no mestrado.

Aos amigos da Fundação Getúlio Vargas (FGV), agradeço não só pela ajuda com pesquisas e pelo debate de opiniões, mas principalmente pelas conversas despretensiosas de onde saem as mais incríveis ideias, seja com pesquisa, incentivo, conselhos e até com esperanças e sonhos compartilhados. 
Agradeço à amiga de mestrado Bruna Loureiro e aos amigos Paulo Aranha, Stephan Gomes de Mendonça, Alexandre de Oliveira Ribeiro Filho e Leonardo Issa Halah que leram esta dissertação como se sua fosse, e muito contribuíram para aparar as necessárias arestas existentes no trabalho.

Ao Futebol de Campo da USP (XI em Campo), que agradeço em nome de Rodrigo Belda, por quase uma década de muitas histórias e títulos. Não tenho como lhes agradecer. 
"Tudo, aliás, é a ponta de um mistério. Inclusive, os fatos. Ou a ausência deles. Duvida? Quando nada acontece, há um milagre que não estamos vendo. "1

${ }^{1}$ ROSA, João Guimarães. “O Espelho”. In: ROSA, João Guimarães. Primeiras Estórias. 1ª Edição. Rio de Janeiro: Livraria José Olympio Editora, 1962. 
COSTA, Fernando Calix Coelho da. O dirigente de empresa como garante de proteção, 2018. 192p. Mestrado - Faculdade de Direito. Universidade de São Paulo, São Paulo, 2018.

\section{RESUMO}

É comum o reconhecimento da posição de garante do dirigente de empresa independente da análise dos pressupostos de punibilidade e da tipicidade da omissão imprópria, como se pode perceber nos casos cognominados como Mensalão e Operação Lava Jato, que estamparam as capas dos principais meios de comunicação do Brasil por um longo período. $\mathrm{O}$ presente trabalho toma este cenário como pano de fundo e tem por escopo examinar a imputação de responsabilidade penal na criminalidade de empresa, sobretudo aquela referente à posição de garantidor de proteção dos dirigentes de empresa, fundamentando e delimitando os seus deveres de proteção.

Para tanto, serão apresentadas, incialmente, as soluções propostas pela doutrina para se responsabilizar os dirigentes de empresas, seja como autor mediato, coautor, partícipe, seja pela via omissiva. Nada obstante, ancora-se em determinado conceito de omissão, assim como são analisadas as teorias que trataram da distinção entre as condutas comissivas e as omissivas.

Percorrido este caminho, os pressupostos da imputação omissiva imprópria serão objetos de análise, especificamente no que toca ao tipo objetivo, como a situação típica, a não realização da ação requerida, a capacidade individual de agir, a possibilidade físico-individual de agir, a imputação objetiva e a posição de garante. O dever de proteção e as suas implicações no âmbito empresarial são a coluna dorsal do presente estudo e, por isso, afasta-se peremptoriamente a existência de um dever genérico de agir por parte do dirigente de empresa. Apresenta-se, também, os fundamentos da posição de garantia do dirigente de empresa, tratando das principais teorias que se dedicaram ao tema.

Por fim, são analisadas as posições de garante de proteção do dirigente em relação aos bens da empresa, assim como à vida, integridade física e saúde dos subordinados, apresentando o âmbito de proteção e os deveres do dirigente de empresa.

Palavras-chave: criminalidade econômica - responsabilidade penal dos dirigentes - omissão imprópria - garante de proteção - patrimônio da empresa - saúde do trabalhador. 
COSTA, Fernando Calix Coelho da. The company manager as guarantor of protection. 2018. 192p. Master. Faculty of Law, University of São Paulo, São Paulo, 2018.

\begin{abstract}
It is common to recognize the position of guarantor of the manager of an enterprise without analyzing the assumptions of punishability and typicity of improper omission, as can be observed in cases such as the called Mensalão and Lava Jato, which have stamped the covers of the main means of communication in Brazil for a long period.

The present work takes this scenario as a background and has as scope to examine the imputation of criminal responsibility in corporate crime, especially that concerning the position of guarantor of protection of company leaders, grounding and delimiting their duties of protection.

Therefore, it will be presented, initially, the solutions proposed by the doctrine to hold the directors of companies accountable, either as a mediate author, coauthor, participant, or by omission. Nevertheless, it is anchored in a certain concept of omission, just as the theories dealing with the distinction between commissive and omissive conduct are analyzed.

Along this path, the presuppositions of improper omissive imputation will be objects of analysis, specifically about the objective type, such as the typical situation, the failure to perform the required action, the individual capacity to act, the physical-individual possibility of acting, the objective imputation and the guarantor position. The duty of protection and its implications in the business sphere are the backbone of the present study and, therefore, the existence of a general duty of action on the part of the manager of enterprise is peremptorily removed. It also presents the fundamentals of the guarantor position of the company leader, dealing with the main theories that were dedicated to the subject.

Finally, the positions of guarantor of protection of the manager in relation to the assets of the company, as well as to the life, physical integrity and health of the subordinates are analyzed, presenting the scope of protection and the duties of the manager of company.
\end{abstract}

Key-words: economic crime - criminal liability of managers - improper omission - guarantee of protection - equity of the company - worker's health. 


\section{SUMÁRIO}

INTRODUÇÃO.............................................................................................................................. 12

1. O PROBLEMA: O DIRIGENTE DE EMPRESA COMO GARANTE .................... 19

1.1 Entre o paradigma da responsabilidade individual e as tendências da

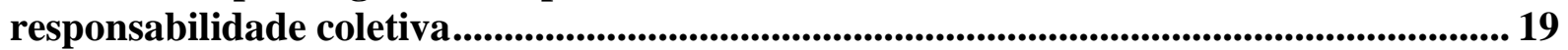

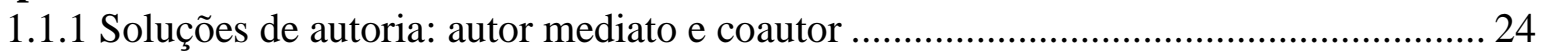

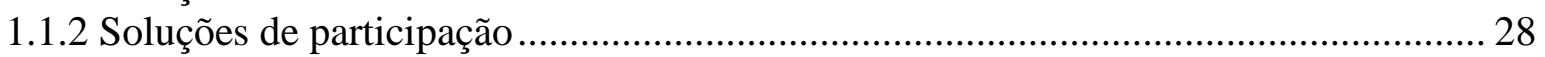

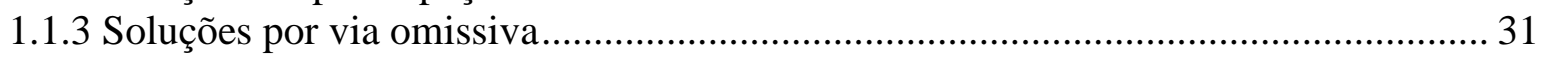

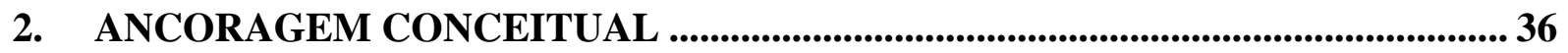

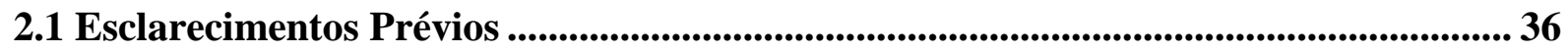

2.20 conceito de omissão de que se parte ........................................................................ 37

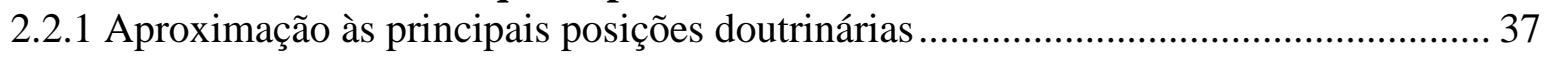

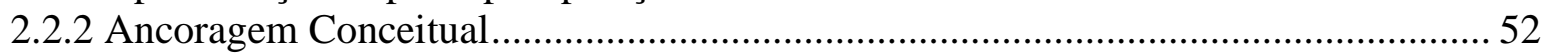

2.3 Principais distinções entre a omissão própria e a imprópria....................................... 53

2.3.1 Breve exposição e apontamentos acerca das propostas de classificação .................... 53

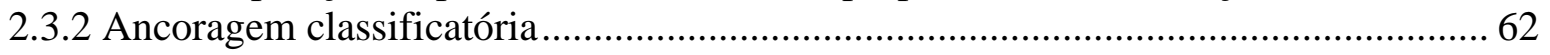

3. APROXIMAÇÃO AOS PRESSUPOSTOS DA IMPUTAÇÃO OMISSIVA

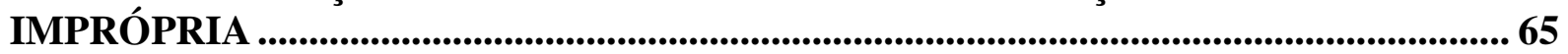

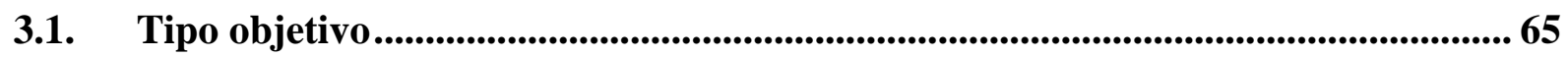

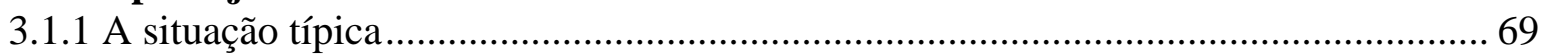

3.1.2 Capacidade individual de agir - possibilidade físico-individual de agir e conhecimento

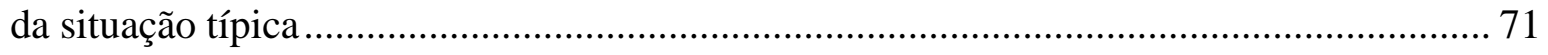

3.1.3 Imputação Objetiva - não diminuição de um risco juridicamente desaprovado e

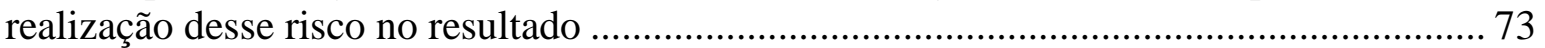

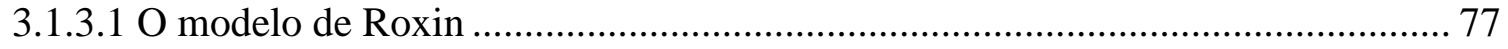

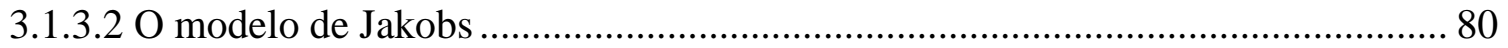

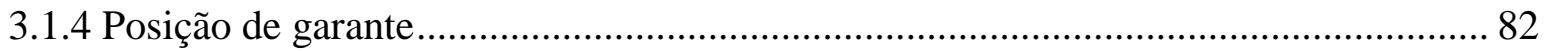

4. A FUNDAMENTAÇÃO DA POSIÇÃO DE GARANTIA...................................... 85

4.1 Fundamento dos deveres de garantia................................................................................ 85

4.1.1. Teoria formal do dever jurídico: a Lei, o contrato e o atuar prévio (Neokantismo).. 85 4.1.2. A divisão funcional: proteção de determinados bens jurídicos e vigilância de fonte de

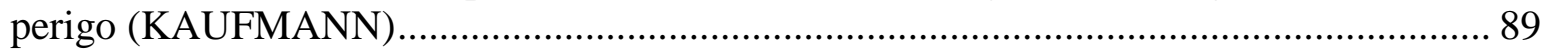
4.1.3. A divisão baseada na natureza dos deveres: competência institucional e competência organizativa (JAKOBS)

4.1.4. O domínio sobre a causa do resultado: proteção sobre do bem jurídico desamparado ou domínio fático sobre um foco de perigo (SCHÜNEMANN) …................................... 97

4.1.5 Silva Sánchez e a barreira de contenção do risco ..................................................... 100 


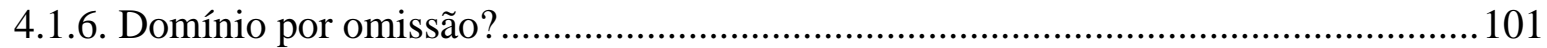

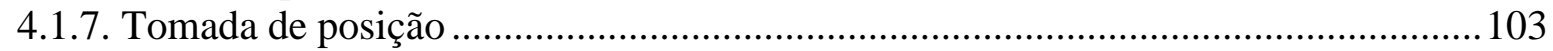

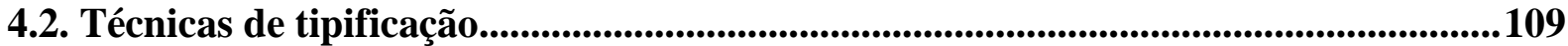

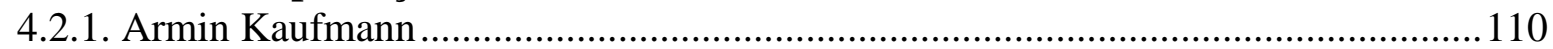

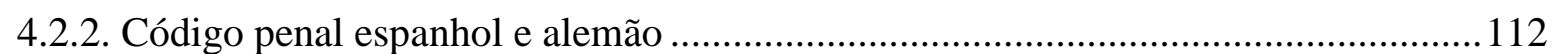

4.2.3. Artigo 13, $\S 2^{\circ}$, do Código Penal brasileiro (CPB) .................................................116

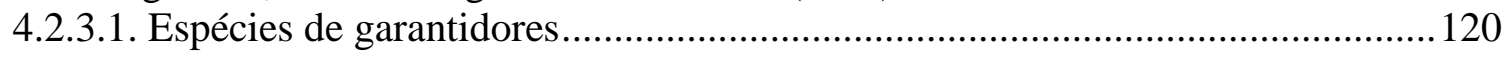

5. OS DIRIGENTES DE EMPRESA COMO GARANTES DE PROTEÇÃO ..............127

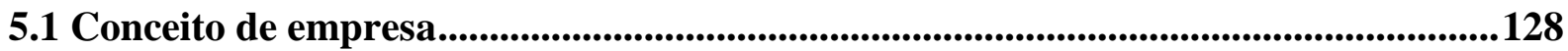

5.2 Conceito de dirigente de empresa .............................................................................132

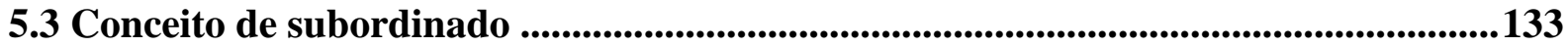

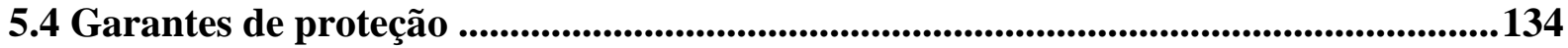

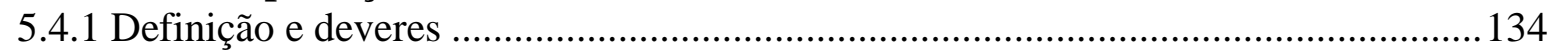

5.4.2 Delegação, divisão de funções e princípio da confiança ......................................... 140

5.5 Os dirigentes como garantes de proteção dos bens da sociedade empresária ..........145

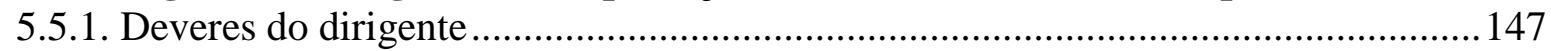

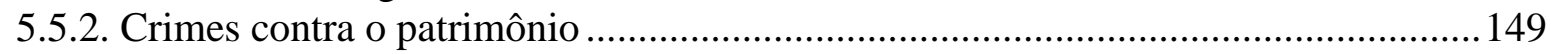

5.5.2.1. A discussão sobre a administração desleal/infidelidade patrimonial ................149

5.5.3 Os dirigentes como garantes de proteção da vida, da saúde e da integridade física do

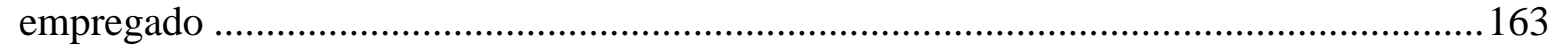

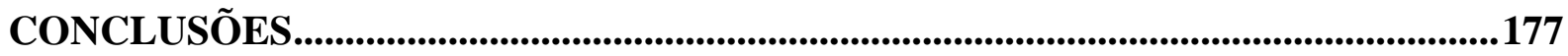

REFERÊNCIAS BIBLIOGRÁFICAS ...................................................................................181 


\section{INTRODUÇÃO}

"Vivemos tempos líquidos. Nada é para durar"2. Dentre as mais diversas interpretações imagináveis deste aforismo do sociólogo polonês ZYGMUNT BAUMAN, a mais evidente é a de que somos incapazes de manter a mesma forma por muito tempo. A temperatura elevada, segundo o autor, não dá ao fluxo uma oportunidade de abrandar, nem o tempo necessário para condensar e solidificar-se em formas estáveis, com uma maior expectativa de vida.

O fenômeno da globalização experimentado no final do século XX pode ser tomado como um arquétipo dessas transformações vertiginosas e constantes, que refletiu diretamente nas relações socioeconômicas e políticas. A perene internacionalização dos Estados, ensejando o surgimento de sociedades intercomunicadas que se influenciam e determinam seus valores culturais reciprocamente, modificou sobremaneira a estrutura das sociedades, atualmente sob influência direta de um modelo econômico e político hegemônico.

Dentre as consequências do aludido cenário de abertura de fronteiras, e somado à ausência da mínima compatibilidade das legislações penais de cada Estado, reconhece-se que a economia globalizada ensejou o aparecimento de possibilidades e inovação referentes à criminalidade, sobretudo às criminalidades transnacional, organizada e de empresa. Assim, o final do século XX e o início do XXI apresenta-se à sociedade uma nova forma de poder hegemônico: a globalização econômica.

O campo da realidade estatal e econômico do mundo contemporâneo fez surgir uma nova espécie de criminalidade, que prescinde do uso da violência corporal tradicional, mas, nem por isso, se mostra menos nociva ao desenvolvimento das relações sociais: a criminalidade econômica, sensível ao desenvolvimento das relações humanas, comerciais, econômicas e financeiras.

Conforme outrora afirmado, dentre os fenômenos observados nesse processo de globalização, destaca-se a liberalização do comércio, dos mercados financeiros e dos movimentos de capital, os processos de privatização das empresas, os avanços tecnológicos, o desenvolvimento de transportes e comunicações e a complexidade alcançada pelo comércio internacional. Nada obstante, multiplica-se, também, o número de empresas que operam nos mercados, estabelecendo um comércio interempresarial, e não mais entre os Estados.

\footnotetext{
${ }^{2}$ PRADO, Adriana. Zygmunt Bauman: "Vivemos tempos líquidos. Nada é para durar" (entrevista). Istoé entrevista- online. 24 de setembro de 2010. Disponível no link https://istoe.com.br/102755 VIVEMOS+TEMPOS+LIQUIDOS+NADA+E+PARA+DURAR+l acessado em 12.9.2017).
} 
Houve, também, o fomento à formação de empresas cotizadas com uma atividade transnacional que não conhece limites geográficos, com flexibilidade organizativa que permite segmentar o processo produtivo e que lhes outorga um enorme poder em todos os níveis. $\mathrm{O}$ poder econômico adquirido por estas entidades e pelos seus gestores é notável, o que implica maior exposição dos mercados pela atuação desses atores. É frequente o reconhecimento na literatura penal, em especial na estrangeira, a emergência, ao longo do século XX, de uma criminalidade de grupo, testemunhada pela ruptura financeira de empresas, muito por causa de atos de gestão danosa dos seus dirigentes.

E essa nova roupagem da criminalidade decorrente das transformações sociais, políticas e econômicas ratificou a ineficiência do sistema de imputação individual do Direito Penal clássico frente à necessidade de se criar novos mecanismos que respondam de forma mais eficiente a essas novas demandas. Nessa perspectiva, a sociedade, desde a perspectiva do Direito Penal do risco, passa a se caracterizar por várias peculiaridades, destacando-se o extraordinário incremento das interconexões causais e a substituição dos contextos de ações individuais por contextos de ações coletivas, nas quais o contato interpessoal se transforma em comportamentos anônimos e estandardizados (produzido a partir de um padrão). SILVA SÁNCHEZ, autor que se dedicou a uma reflexão mais detida sobre o tema, chega a afirmar que o delito econômico praticado por uma empresa ou por meio dela é o novo paradigma para a construção da contemporânea dogmática do Direito Penal, substituindo o tradicional homicídio cometido por autor individual $^{3}$.

E não é por outra razão que a criminalidade empresarial tem desafiado a dogmática penal. A proteção aos bens jurídicos individuais cedeu lugar à tutela de valores supraindividuais e essa transição de premissas de proteção resultou em uma nova estruturação normativa da tutela penal, sem que o Direito Penal Econômico tivesse uma plena autonomia principiológica em relação à matriz liberal da intervenção punitiva.

E, como não poderia ser diferente, a dogmática jurídico-penal moderna teve de acompanhar tais transformações para tratar adequadamente os novos fenômenos da sociedade contemporânea, tendo em vista as insatisfatórias e criticáveis respostas tradicionais. Isso

\footnotetext{
${ }^{3}$ SILVA SÁNCHEZ, Jesús-María. A expansão do Direito Penal: aspectos da política criminal nas sociedades pós-industriais. Tradução Luiz Otavio de Oliveira Rocha. São Paulo: RT, 2002, p.72 e 84. O Direito Penal Econômico passou, então, a proteger valores distintos daqueles protegidos no Direito Penal Clássico, como no caso do crime de homicídio, considerado o padrão da delinquência. Entre nós, Nelson Hungria afirmava que " $O$ homicídio é o tipo central dos crimes contra a vida e é o ponto culminante na orografia dos crimes. É o crime por excelência. É o padrão da delinqüência violenta ou sanguinária, que representa como que uma reversão atávica às eras primevas, em que a luta pela vida, presumivelmente, se operava com o uso normal dos meios brutais $e$ animalescos. É a mais chocante violação do senso moral médio da humanidade civilizada”.
} 
porque, a teoria do delito tem seus fundamentos fixados no indivíduo e, uma vez que as pessoas jurídicas não contam com os atributos que caracterizam aquele indivíduo, é evidente a necessidade de se encarar a nova configuração da sociedade moderna, que não mais reflete aquela que viu nascer as primeiras construções da dogmática jurídico-penal. Nos recentes modelos de configuração estrutural das empresas a conduta puramente executiva (no sentido de executar uma tarefa específica) nem sempre é a mais relevante. Ao contrário disso, o papel daqueles situados em posição hierárquica superior e que detém o controle do ente coletivo, em muitos dos casos, é fundamental.

Tendo em vista essa nova configuração, parte da doutrina propôs que restasse impune aquele que executasse imediatamente a tarefa, uma vez que escaparia da sua capacidade de resistência a tal execução, por estar obrigado a obedecer dentro de uma escala hierarquizada e sua fungibilidade por ocupar posição inferior na organização. ${ }^{4}$

Assim sendo, é de se reconhecer que as empresas e as pessoas jurídicas são uma nova realidade emergente, cujo tratamento não pode mais ser o de uma mera soma de sujeitos individuais, mas sim uma realidade social distinta daquela. E essa constatação vem dando lugar à necessidade de repensar as estruturas de imputação construídas até então. O delito de empresa passa a ser reconhecido como um delito estrutural, gerando problemas de imputação, sejam eles de caráter objetivo ou subjetivo, que são reflexos do atual sistema de organização do trabalho, acarretando o que fora denominado de irresponsabilidade organizada ${ }^{5}$.

É sob essa perspectiva que se conclui, preliminarmente, que a localização da responsabilidade individual nos níveis mais baixos dentro da estrutura hierárquica da empresa deslegitima a intervenção e a credibilidade do Direito Penal. A eficácia do Direito Penal restaria seriamente ameaçada quando o risco de receber sanções penais se desliza para os níveis hierárquicos mais baixos, carente de poder. Até porque, de todos os atores que intervêm no desenvolvimento da atividade empresarial, o menos adverso ao risco costuma ser o sócio ${ }^{6}$.

\footnotetext{
${ }^{4}$ SCHÜNEMANN, Bernd. Cuestiones básicas de dogmática jurídico penal y de política criminal acerca de la criminalidad de empresa, Anuario de Derecho Penal y Ciencias Penales, XLI. Madrid: Ministerio de Justicia, 1988 , p. 531.

5 Trata-se de uma expressão criada por ULRICH BECK, em 1988, no bojo da obra Gegengifte. Die organisierte Unverantwortlichkeit. O autor da presente dissertação teve acesso ao termo na obra de FEIJOO SÁNCHEZ, que destaca o papel das empresas na vida econômica atual, sublinhando a dificuldade para se descobrir o autor do delito dentro das empresas, o que permite transferir ao âmbito da criminalidade das empresas a ideia de que a organização delas mesmas é uma expressão da irresponsabilidade organizada. FEIJOO SÁNCHEZ, Bernardo. Sanciones para empresas por delitos contra el medio ambiente. Madrid, Civitas, 2002, p. 36.

${ }^{6}$ Chamada "transferência de riscos", originária da expressão inglesa Risk Shifiting. BOTTINI oferece uma análise ampla e detalhada do referido termo, distinguindo-o da delegação, pois, segundo o autor, "A transferência do risco é distinta da delegação. Aquele que recebe a incumbência não age no interesse do outro, mas em seu próprio, de forma que incorpora o risco - e os bônus/ônus dessa transferência - completamente ao seu âmbito de gestão. Passa a manejá-lo sem qualquer orientação ou limite porque não tem a obrigação de responder ao transferente."
} 
A propósito, a doutrina espanhola apresenta a figura do bode expiatório ${ }^{7}$, distinguindo entre os voluntários, que aceitam assumir a responsabilidade mediante o pagamento de alguma recompensa e aqueles sem contraprestação alguma. Assim, os funcionários subordinados, periféricos em relação ao corpo dirigente da empresa, em conexão com desvio organizacional, serão tratados como dispensáveis. As corporações, se deixadas à sua própria sorte, tentarão desviar a responsabilidade para o seleto grupo de pessoal de sacrifício. $^{8}$

Em virtude destas prévias considerações, é de se reconhecer as dificuldades em determinar quem é o responsável por uma conduta delituosa no âmbito das ações empresariais. A situação ganha contornos mais preocupantes quando se avalia a imputação de determinada conduta a este responsável. E este cenário de insegurança encontra suas origens, também, na atecnicidade da aplicação dos conceitos da teoria do crime, assim como na importação de teorias desenvolvidas sob o manto de uma estrutura jurídica distinta da brasileira, o chamado transplante jurídico 9 .

$\mathrm{E}$ as razões que conduzem o presente trabalho refletem uma das vertentes do estudo nesse novo cenário que enfrenta o Direito Penal contemporâneo: delimitar os deveres de garante de proteção do administrador de empresa. Isso porque, acredita-se que o ponto mais transversal e controvertido, seja pelo ponto de vista Político Criminal ou pela perspectiva dogmática, é o da responsabilidade por omissão imprópria atribuível ao administrador da empresa $^{10}$. E não poderia ser diferente, dado que o tema da omissão imprópria - comissão por omissão $^{11}$ - apresenta múltiplas questões dogmáticas, como as que se elenca a seguir a título

BOTTINI, Pierpaolo Cruz. Do tratamento penal da ingerência. Tese de livre docência, Universidade de São Paulo, Faculdade de Direito, 2015, p. 264.

${ }^{7}$ Em sentido figurado, a expressão é utilizada nos casos em que alguém é escolhido arbitrariamente para se responsabilizar por algo que geralmente não tenha cometido. Também utilizada na cultura espanhol (chivo expiatório) e na cultura norte americana (scapegoatinhg).

${ }^{8}$ FISSE, Brent; BRAITHWAITE, John. Corporations, Crime and Accountability. Melbourne: Cambridge University Press, 1993, p. 29: "Corporations, if left to their own devices, will try to deflect responsibility to a select group of sacrificial personnel, often at a lower level than the actual source of skulldugger."

${ }^{9}$ Sobre a chamada teoria dos transplantes jurídicos, ver GRECO, Luís; LEITE, Alaor. A "recepção" das teorias do domínio do fato e do domínio da organização no Direito Penal econômico brasileiro: Observações sobre as formas de intervenção no delito na Ação Penal 470 do Supremo Tribunal Federal brasileiro ("Caso Mensalão"). In.: Zeitschrift für Internationale Strafrechtsdogmatik. v. 7-8, 2015, p. 386-393.

${ }_{10}$ Para maior aprofundamento: MARTÍNEZ-BUJÁN PÉREZ, Carlos. Derecho penal económico y de la empresa. Parte General. Valencia: Tirant lo Blanch, 2007, p. 493.

${ }^{11}$ O presente trabalho tem preferência pela utilização do termo "omissão imprópria" para se referir às omissões de garante. Segue-se, aqui, a linha adotada por TAVARES ao registrar que "Modernamente, tem-se questionado, inclusive, essa denominação de crimes omissivos impróprios, afirmando-se que ela não é a mais adequada, sendo mais inadequada ainda a denominação de crimes comissivos por omissão, pois não se trata de crime comissivo, senão de crime omissivo." TAVARES, Juarez. As Controvérsias em torno dos Crimes Omissivos. Rio de Janeiro: Instituto Latino-americano de Cooperação Penal, 1996, p. 64-65; O autor reproduz o mesmo pensamento na obra Teoria dos crimes omissivos. TAVARES, Juarez. Teoria dos Crimes Omissivos. Madrid, Barcelona, 
ilustrativo: a causalidade entre o não fazer e o resultado produzido; a fundamentação do dever jurídico; as fontes do dever de atuar para evitar o resultado material; a possível equivalência ou equiparação entre a ação e a omissão; a distinção entre um fazer positivo e a omissão; a posição de garante; e a própria estrutura dos delitos de omissão imprópria.

Tendo em vista as mencionadas questões, é comum o reconhecimento da posição de garante de proteção do administrador de empresa, objeto de análise deste trabalho, por meio de critérios gerais. A razão para isso é das mais simples: a lei penal não oferece, e nem poderia oferecer, um catálogo satisfatório com todas as possíveis posições de garante, cabendo ao intérprete da lei encontrá-las. E é diante desse vácuo legislativo ${ }^{12}$ e, até certo ponto, doutrinário/jurisprudencial, que se tem recorrido à caracterização do administrador/executivo/superior ${ }^{13}$ como garante de proteção de forma automática e discricionária, reconhecendo que aquele administrador teria, indistintamente, o dever de impedir cursos causais perigosos produzidos por coisas ou pessoas da empresa. Não há nada que defina, em última análise, o que permite atribuir à inatividade de determinados sujeitos, especialmente obrigados a um dever de agir, para impedir um resultado material tal como se o tivessem causado ativamente.

A normatização do Código Penal Brasileiro (CPB), com a reforma de 1984, passou a tratar do elemento do tipo omissivo impróprio, elencando as fontes do dever de agir nas alíneas do $\S 2^{\circ}$ do art. $13^{14}$. Em que pese a referida previsão legal, não foram estabelecidos parâmetros para identificar a relação entre a lei e o dever do indivíduo de evitar o resultado ${ }^{15}$.

Buenos Aires, São Paulo: Marcial Pons. 2012, p. 312 ss. ESTELLITA, seguindo o posicionamento de KAUFMANN e de BOTTINI, adverte que "A expressão crimes comissivos por omissão parece colocar em destaque a equiparação legal, em termos de desvaloração, da resposta penal para a comissão que causa um resultado e para a omissão de garantidor que não evita esse resultado, mas isso não quer dizer que no crime omissivo impróprio alguma parte da desvaloração típica recaia sobre um agir." ESTELLITA, Heloísa. Responsabilidade penal de dirigentes de empresas por omissão: estudo sobre a responsabilidade omissiva imprópria de dirigentes de sociedades anônimas, limitadas e encarregados de cumprimento por crimes praticados por membros da empresa. São Paulo: Marcial Pons, 2017, p.75.

$12 \mathrm{O}$ referido vácuo legislativo é justificável. Aqui, não haverá qualquer pretensão de se apresentar novas teorias acerca da posição de garante, nem tampouco se limitar a criticar a previsão legislativa do Código Penal brasileiro. ${ }^{13}$ A análise dos conceitos será realizada em item próprio no transcorrer do trabalho.

14 Art. 13 - O resultado, de que depende a existência do crime, somente é imputável a quem lhe deu causa. Considera-se causa a ação ou omissão sem a qual o resultado não teria ocorrido.

(...)

$\S 2^{\mathbf{0}}$ - A omissão é penalmente relevante quando o omitente devia e podia agir para evitar o resultado. O dever de agir incumbe a quem:

a) tenha por lei obrigação de cuidado, proteção ou vigilância;

b) de outra forma, assumiu a responsabilidade de impedir o resultado;

c) com seu comportamento anterior, criou o risco da ocorrência do resultado. Acesso em: http://www.planalto.gov.br/ccivil_03/decreto-lei/Del2848compilado.htm

15 Segundo BOTTINI, "o Código Penal brasileiro expõe que o dever de garante, que fundamenta a responsabilidade na omissão imprópria, decorre da lei, da assunção, ou da criação de um risco precedente. Ainda que existam parâmetros taxativos, deve-se identificar de que forma a lei se relaciona com o dever de evitar o 
E aqui revelam-se os primeiros questionamentos: o dever de garante de proteção é direcionado a todo e qualquer perigo ao bem jurídico tutelado? É possível afirmar a existência de um dever genérico de solidariedade? Deve haver dependência entre os sujeitos? Qual o fundamento da posição de garante de proteção dos dirigentes? Qual a fonte do dever de proteção do dirigente? Qual o alcance do seu dever de atuar? Quais condições são necessárias para que se possa afirmar a identidade estrutural entre sua conduta omissiva e a não evitação do resultado lesivo a determinado bem jurídico?

Essas são algumas perguntas que carecem de respostas para delimitar a responsabilidade penal do dirigente de empresa quando presente a posição de garantidor. ${ }^{16} \mathrm{E}$ tais questões reforçam a importância do tema e a necessidade de uma análise detida de seus fundamentos.

Com efeito, a opção pelo tema da posição de garante derivada do dever de proteção decorre, conforme já consignado, da aplicação indiscriminada, pelos nossos Tribunais, das mais diversas teorias que fundamentam uma posição de garantia, prescindindo da mais rasteira análise técnica. A dificuldade em identificar e delimitar o dever de atuar dos dirigentes de empresas de acordo com o conteúdo do dever de proteção indicado no art. $13, \S 2^{\circ}$, inciso $a$, do Código Penal abre margem para referida discricionariedade.

A bem da verdade, pode-se considerar que os delitos omissivos impróprios são uma das fontes mais importantes de expansão da manifestação punitiva de difícil controle, colocando em xeque o princípio da mínima intervenção ${ }^{17}$. Casos referentes à imputação de responsabilidade penal por omissão imprópria a dirigentes de empresa já estampam as capas das principais revistas e jornais do Brasil, como se pôde observar na tão comentada Ação Penal 470 - Mensalão - e na denominada Operação Lava Jato e seus desdobramentos. Tais exemplos,

\footnotetext{
resultado, quais as características da assunção que transformam alguém em garante, e qual o caráter do risco precedente criado, para imputar o resultado posterior ao omitente." BOTTINI, Do tratamento geral da ingerência, p.2.

${ }^{16} \mathrm{O}$ tema da omissão, por si só, representa uma inquietação deliberada diante do incontestável estado de perigo instalado no Brasil que, baseado na falácia de se tornar um movimento de combate aos crimes praticados "pelas elites", vem desconsiderando sobremaneira direitos e garantias individuais. TAVARES demonstrou a mesma preocupação ao afirmar que, quanto aos deveres de garantidor, "a primeira grande discussão está em se determinar, praticamente, sua fonte e seus limites. Se as condições pessoais de vinculação entre o omitente e a vítima ou entre o omitente e a fonte produtora do perigo implicam a geração de um dever de impedir o resultado, a responsabilidade pelo fato ocorrido só pode se dar sob dois pressupostos: a) da mais precisa identificação dessas condições; $b$ ) da efetiva demonstração de que o agente era capaz de realizar a ação necessária a evitar o resultado, conforme suas características típicas. Como, ademais, a responsabilidade, nessa hipótese, deve estar associada." TAVARES, Teoria dos crimes omissivos, p. 45.

17 TAVARES não limita as razões da expansão dos delitos omissivos em argumentos de ordem prática, por exigência política criminal. O autor sustenta a comunhão entre o Direito Penal, a política criminal e os seus pressupostos, na medida em que há uma necessidade prática de encontrar soluções aos problemas apresentados pela sociedade em determinado momento, uma necessidade teórica de se definir os pressupostos e o vínculo entre o trabalho científico e às suas finalidades. TAVARES, Teoria dos crimes omissivos, p. 36.
} 
por si só, explicitam a transversalidade do tema e a sua importância no atual cenário dos delitos cometidos no âmbito das empresas com organização hierarquizada e complexa.

É de se ressaltar, por oportuno, que a opinião amplamente majoritária da doutrina se pronuncia a favor de se responsabilizar por omissão o dirigente de empresa que não evita as condutas delituosas cometidas no âmbito de atuação daquela empresa. A discussão se centra, vale dizer, em determinar a origem do dever de atuar e amplitude da obrigação de evitar fatos delitivos, motivo de discrepâncias em torno de casos como o suborno de funcionários, ações violentas de um segurança na discoteca e ações fraudulentas frente aos clientes da empresa.

O que se buscará neste trabalho é argumentar em torno dos pressupostos, fundamentos e limites de uma eventual posição de garante de proteção do dirigente de empresa nos casos em que se possa basear uma responsabilidade na omissão imprópria do tipo.

É evidente que o intuito da presente dissertação não será dar uma última palavra sobre o complexo tema das omissões impróprias, até porque seria muito pretensioso. Nessa perspectiva, haja vista as limitações de tempo e espaço, o enfrentamento do tema exigirá a fixação de conceitos, optando por determinada linha de pensamento e metodologia. Assim sendo, não serão objeto de análise dessa dissertação as questões referentes à: i) distinção entre ação e omissão; ii) discussão a respeito dos elementos subjetivos da omissão imprópria; e iii) análise da antijuridicidade, culpabilidade e punibilidade. A dissertação se limitará, portanto, à análise dos aspectos objetivos da tipicidade da omissão imprópria quanto aos deveres de garante de proteção.

Para tanto, serão apresentadas, preliminarmente, as possíveis soluções oferecidas pela doutrina para se responsabilizar os diretores de empresa a título de garante de proteção. Em seguida, será feita a ancoragem conceitual necessária para o posterior desenvolvimento da dissertação. Sucessivamente, realizar-se-á a aproximação aos pressupostos da imputação omissiva imprópria. Fixadas as bases inicias, serão analisadas as teorias que fundamentam os deveres de garantia e suas técnicas de tipificação, com posterior tomada de posição. Em seguida, o dever de proteção e as suas implicações no âmbito empresarial serão o objeto de exame, coluna dorsal do presente estudo. Tentar-se-á delimitar, nesse ponto, o âmbito de proteção dos administradores, afastando a existência de um dever genérico, utilizado como via para solucionar o vazio de responsabilidade dos administradores.

Finda esta introdução, passa-se, então, a enfrentar o problema: o dirigente empresarial como garante de proteção. 


\section{CONCLUSÕES}

Por todo o exposto, conclui-se que:

01. As transformações econômicas do mundo contemporâneo fizeram surgir uma nova espécie de criminalidade, que prescinde do uso da violência corporal tradicional: a criminalidade econômica, sensível ao desenvolvimento das relações humanas, comerciais, econômicas e financeiras. A crescente difusão dos crimes cometidos no âmbito empresarial acarreta severas discussões no que toca à complexa imputação da responsabilidade penal.

02. A criminalidade econômica vem desafiando a dogmática penal tradicional, uma vez que o olhar do paradigma clássico do Direito Penal é de um crime de estelionato clássico ou de homicídio: autor individual ou coautor, dolo direto de $1^{\circ}$ grau, execução direta, autoria imediata, bem jurídico individual, nexo de causalidade para estabelecer a relação entre a conduta e o resultado, crime malum in se e crime comissivo doloso.

03. Os crimes omissivos próprios e impróprios são da essência do Direito Penal econômico, sendo praticados, sobretudo, em concurso em agentes. Os crimes omissivos próprios fundam-se em um dever geral de existência (v.g., omissão de socorro) e os crimes omissivos impróprios transformam crimes de ação em crimes omissivos apenas para indivíduos com características especiais, quais sejam os garantes.

04. Os crimes econômicos são, em regra, praticados mediante a intervenção de mais de um sujeito, pois há: i) uma divisão horizontal de atribuições/responsabilidades; ii) uma divisão vertical de funções. Há, também, a dissociação entre a ação e a responsabilidade, pois: i) a execução direta do crime é feita pelo subordinado; e ii) a autoria recai no indivíduo que não executa diretamente o injusto. Dissocia-se, portanto, a ação (quem comete) e a responsabilidade por esta conduta e normalmente não será o responsável que irá praticar a conduta (v.g., sócio administrador de uma empresa que determine que o contador falsifique os livros da empresa para não pagar tributos).

05. É fundamental que se diferencie os conceitos de ação e omissão, porquanto a preferência por determinada linha de pensamento afetará toda a construção da dogmática que 
envolve a posição de garante dos dirigentes. Assim, a omissão surge da manifestação de personalidade do sujeito, devendo estar presentes os requisitos da expectativa de ação e da capacidade de agir do indivíduo. Há casos, entretanto, em que a expectativa de ação deve estar vinculada a um dever normativo, como na maioria dos casos referentes aos delitos omissivos impróprios.

06. A teoria geral do delito é o instrumento para se responder se determinado fato é um delito ou não, é o juízo de subsunção do juiz, com uma ordem de interrogações e sucessivas respostas para determinar se é ou não um delito. Todo o arcabouço penal serve para o julgador subsumir um conjunto de fatos (premissa menor) à determinada norma penal (premissa maior), verificando se aqueles fatos se encaixam na norma penal. A teoria geral do delito, portanto, diferencia a localização dos elementos e a relação entre eles, estabelecendo o processo de imputação e valoração de uma forma ordenada.

07. Para determinar se uma conduta se amolda ao tipo objetivo omissivo impróprio e possa ser imputado ao sujeito que ostente uma posição de garante, é fundamental a concorrência dos seguintes elementos: i) situação típica; ii) capacidade individual de agir; iii) imputação objetiva; e iv) posição de garante. Em regra, nos delitos omissivos impróprios a situação típica consiste no perigo de produção do resultado. Para que se identifique a capacidade individual de ação devem ser consideradas as capacidades especiais do sujeito (forças físicas, conhecimentos técnicos ou faculdades intelectuais).

08. Imputar é responsabilizar juridicamente. A imputação objetiva agrega a conduta como lesiva ao bem jurídico (condutas perigosas ou danosas) e não proíbe resultados, mas sim condutas perigosas. Causar não é ser juridicamente responsável por um resultado, pois é possível causar um resultado, mas não ser imputado ao causador.

09. O resultado será imputado ao agente: (i) quando ele criar um risco não autorizado pelo sistema ao bem jurídico; (ii) quando o risco se realiza no resultado concreto; e (iii) este resultado se encontra dentro do alcance do tipo. A teoria da imputação objetiva: (i) não substitui o nexo de causalidade; (ii) limita o âmbito de alcance do tipo objetivo; (iii) traz uma parte do elemento de antijuridicidade para dentro do juízo da imputação objetiva (risco não permitido). 
10. A doutrina majoritária brasileira foi abandonando a teoria dos deveres formais, tendo em vista a sua imprecisão e as lacunas que não permitem precisar em quais casos o indivíduo será responsabilizado por sua omissão. KAUFMANN foi o responsável por criar a divisão das posições de garantidor, facilitando o estudo acerca do tema, ao dividir as posições de garante segundo a direção dos deveres.

11. A teoria das funções como critério de formulações dos deveres de garante apresentada pelo autor foi uma importante contribuição para o conceito de posição de garante, afastando-se do mero status pessoal, e aproximando-se da posição do sujeito em relação a determinada situação e distingue entre deveres de garante, cuja função consiste na proteção de determinados bens jurídicos (deveres de custódia), e aqueles nos quais o garante está obrigado a controlar uma fonte de perigo (deveres de vigilância).

12. A posição de garantidor é fundamentada pela assunção fática de uma fonte de perigo ou da proteção de um bem jurídico. A regulamentação extrapenal, por seu turno, delimita o conteúdo e o âmbito do dever caso a caso.

13. O garante de proteção é aquele que tem o dever de defender um ou mais bens jurídicos contra todos os ataques que possam sofrer, diante da relação existente entre o sujeito titular do bem (trabalhador da empresa ou a própria empresa, nos casos envolvendo o seu patrimônio) e o garante de proteção. Os deveres de proteção podem ser assumidos por outros indivíduos que não aqueles originalmente obrigados, conforme previsão do artigo $13, b$, do CPB.

14. Tendo em vista a distância entre o a criação do perigo e o resultado nos delitos econômicos, a fundamentação da posição de garante por ingerência parece insuficiente para abarcar um número expressivo de casos.

15. As empresas estruturam as atividades por meio da divisão do trabalho e de funções. Diante da divisão do trabalho quanto aos objetos e procedimentos da empresa, somente é possível eliminar o perigo por meio de uma coordenação das ações particulares, de modo que a institucionalização de um dirigente em determinado cargo atribui a ele um domínio. O fundamento do dever de garante está no domínio sobre o desamparo da vítima, não havendo relação com o comportamento anterior do garante, mas sim com a inércia diante do seu domínio. Não se deve confundir o critério do domínio do fato com 
o critério dos delitos de infração de dever. Estes servem para identificar quem é a figura central e, crimes de infração de dever, não é quem domina o fato, mas quem tem o dever de agir e infringindo este dever (v.g., crimes próprios de funcionário público) ou está descumprindo este dever (crimes omissivos, próprios ou impróprios).

16. Não há previsão legal para o tipo de administração desleal no Brasil. O fundamento da administração desleal é a violação dos deveres por aquele que ostenta a administração dos bens, incluindo o dever de não realizar atos que lesionem o patrimônio. Somente poderá ser autor do tipo de administração desleal aquele que infringe o dever que lhe incumbe de velar pelo patrimônio alheio, ou seja, a posição de domínio. Deve haver, portanto, o domínio sobre o patrimônio alheio e o exercício não permitido do patrimônio mediante o poder jurídico contra o seu titular. O alcance da posição de garantia do administrador vem definido pelo seu ato de assunção, não necessariamente pelos deveres jurídicos civis ou de leis extrapenais próprios de sua posição. Para determinar o conteúdo e o sentido da atuação devida deve-se analisar o ato de assunção do administrador e os seus deveres de atuar para evitar o prejuízo do patrimônio, de acordo com os standards próprios da sua posição.

17. Caso o dirigente não tenha uma relação de domínio material sobre a atividade, não será ele penalmente responsável por eventuais lesões sofridas pelo trabalhador no transcorrer do trabalho. O critério decisivo é a relação de domínio, entendido como o conjunto de condições, limitados pelo tipo de injustos, que fundamentam uma relação específica de dependência do bem jurídico em relação a um sujeito, ou uma classe de sujeitos. 


\section{REFERÊNCIAS BIBLIOGRÁFICAS}

BACIGAluPo ZAPATER, Enrique. Curso de Derecho Penal económico. Marcial Pons. Barcelona. 1998.

Conducta precedente $y$ posición de garante en el

Derecho Penal. Anuario de Derecho Penal y Ciencias Penales, XXIII. Madrid: Ministerio de Justicia. 1970.

Delitos impropios de omisión. Colección Cuadernos Luís Jiménez de Asúa, n. 25. Madrid: Dykinson. 2006.

Falsedad documental, estafa y administración desleal. Ed. Marcial Pons, Madrid, 2007.

La problemática de la administración desleal en el derecho penal español (Consideraciones comparativas entre el Derecho alemán y el español), en Estudios Jurídicos: Hacia un Derecho penal económico europeo, Jornadas en honor del Profesor KLAUS TIEDEMANN en la UAM del 14-17 de octubre de 1992, BOE, Madrid, 2005.

BITTENCOURT, Cezar Roberto. Tratado de Direito Penal - vol. 1. São Paulo, Saraiva, 2012.

BELING, Ernst Von. Esquema de Direito Penal. A doutrina do delito-tipo. Campinas: Servanda, 2010.

BIERRENBACH, Sheila. Crimes omissivos impróprios: Uma análise à luz do Código penal brasileiro. Belo Horizonte: Del Rey, 1996.

BOTTINI, Pierpaolo Cruz. Do tratamento penal da ingerência. Tese de livre docência, Universidade de São Paulo, Faculdade de Direito, 2015. 
BUSATO, Paulo César. Direito Penal: parte geral. São Paulo: Atlas, 2013.

Direito Penal e ação significativa. Rio de Janeiro: Lumen Juris, 2010.

CARVAlho, Américo A. Taipa de. A ciência global do Direito Penal. In CARVALHO, Américo A. Taipa de. Direito Penal: parte geral: questões fundamentais, teoria geral do crime. Coimbra: Coimbra Editora, 2008.

CARVAlhoSA, Modesto. Comentários à lei de Sociedades Anônimas. Vol. 3, 6 Edição. São Paulo: Saraiva, 2014.

CASTALDO, Andréa. Criminalidad organizada y mercado económico - financiero, in Guillermo J. Yacobucci (Coord.), El crimen organizado. Desafíos y perspectivas en el marco de la globalización, Ed. Ábaco, Bs. As., 2005.

CEBAllos, Elena B. Marín de Espinosa. Criminalidad de Empresa: la responsabilidade penal en las estructuras jerarquicamente organizadas. Valencia: Tirant Lo Blanch, 2002.

CEREZO MIR, J., Curso de Derecho penal español. Parte general. Lecciones 26-40, Madrid, 2000 .

CORRÊA-LIMA, Osmar Brina. Sociedade Anônima. 3ª Edição. Belo Horizonte: Del Rey, 2005.

CUADRADO RUIZ, María Angeles. La comisión por omisión como problema dogmático. Anuario de Derecho Penal y Ciencias Penales, L. Madrid: Ministerio de Justicia. 1997.

D’AVILA, Fábio Roberto. O Direito e a legislação penal brasileiros no século XXI - Entre a normatividade e a política criminal. In GAUER, Ruth Maria Chittó (org.). Criminologia e sistemas jurídico-penais contemporâneos. 2 ed. Porto Alegre: EdiPUCRS. 2012. 
DELmanto, Celso. et al. Código Penal comentado: acompanhado de comentários, jurisprudência, súmula em matéria penal e legislação complementar. 8. ed. Saraiva, São Paulo, 2010.

DEMETRIO CRESPO, Eduardo. Fundamento de la responsabilidad en comisión por omisión de los directivos de las empresas. In: SERRANO-PIEDECASAS, José Ramón. Cuestiones actuales de Derecho Penal empresarial. Madrid: Colex. 2010.

Sobre la posición de garante del empreario por la no evitación de delitos cometidos por sus empleados. Centro de Investigación Interdisciplinaria en Derecho Penal Económico. Artigo disponível em: http://www.ciidpe.com.ar/area1/posicion\%20de\%20garante.Demetrio\%20Crespo.pdf.Acesso em 20/09/2017.

DOPICO GÓMEZ-ALLER, Jacobo. Omisión e Injerencia en Derecho Penal. Valencia:Tirant lo Blanch. 2006.

ESTELLITA, Heloísa. Responsabilidade penal de dirigentes de empresas por omissão: estudo sobre a responsabilidade omissiva imprópria de dirigentes de sociedades anônimas, limitadas e encarregados de cumprimento por crimes praticados por membros da empresa. São Paulo: Marcial Pons, 2017.

FEIJOO SÁNCHEZ, Bernardo. Sanciones para empresas por delitos contra el medio ambiente. Madrid, 2002.

FERRAJOLLI, Direito e razão. $4^{\mathrm{a}}$ ed. Trad. Ana Paula Zomer, Juarez Tavares, Luiz Flávio Gomes e Fauzi Hassan. São Paulo: Revista dos Tribunais, 2014.

FERRAZ JUNIOR, Tércio Sampaio. Introdução ao Estudo do Direito. 7 ed. São Paulo: Atlas, 2013. p. 25.

FEUERBACH, Paul Johann Anselm von. Tratado de Derecho Penal común vigente en Alemania. Buenos Aires: Hammurabi. 2007. 
FIGUEIREDO DIAS, Jorge de. Direito Penal: parte geral. 2. ed. São Paulo: Revista dos Tribunais; 2007. v. 1: questões fundamentais: a doutrina geral do crime.

Questões funda mentais: a doutrina geral do crime, parte geral, tomo I. Revista dos Tribunais: São Paulo, $2^{\mathrm{a}}$ Ed., 2007.

FISSE, Brent; BRAITHWAITE, John. Corporations, Crime and Accountability. Melbourne: Cambridge University Press, 1993.

GINÉS FABRELLAS, Anna. Instrumentos de compensación del daño derivado de accidente de trabajo y enfermedad profesional. La Ley, Madrid, 2012.

GIMBERNAT ORDEIG, Enrique. Causalidad, Omisión e Imprudencia. Revista Brasileira de Ciências Criminais, n. 17. São Paulo: Revista dos Tribunais. 1997.

La omisión impropia en la dogmática alemana. Una exposición. In: Ibidem. Ensayos Penales. Madrid: Tecnos. 1999.

GOMEZ-JARA DÍEZ, Carlos. Fundamentos Modernos de la responsabilidad penal. Montevidéu-Buenos Aires: Bdef, 2010.

GRECO, Luís. Um panorama da teoria da imputação objetiva. São Paulo: RT, 2013. ; ESTEllita, Heloisa. Direito Penal - Parte Geral: estudo por meio do método de resolução de casos. Working Paper.

; LEITE, Alaor. Claus Roxin., 80 anos. Revista Liberdades. São Paulo, n. 7, pp. 97-123, mai./ago. 2011.

GRECO, Rogério. Curso de Direito Penal / Rogério Greco. - 17. ed. Rio de janeiro: lmpetus, 2015. 
HUERTA TOCILDO, Susana. Problemas fundamentales de los delitos de omisión, Madrid, 1987.

. Principales novedades de los delitos de omisión en el Código

Penal de 1995. Valencia: Tirant lo Blanch. 1997.

HUNGRIA, Nélson. Comentários ao código penal, volume V, arts. 121 a 136. $3^{\mathrm{a}}$ ed. Rio de Janeiro: Editora Forense, 1955.

JAKOBS, Günther. Derecho Penal. Parte General. Fundamentos y Teoria de la imputación Madrid: Marcial Pons, 1995.

Sociedad, norma, persona en uma teoría de un derecho penal funcional. Bogotá: Universidad Externado de Colombia. 1996.

La Imputación Objetiva en el Derecho Penal. Trad. Manuel Cancio Meliá. Madrid: Civitas. 1996.

La imputación objetiva, especialmente en el ámbito de las instituciones jurídico - penales del "riesgo permitido", la "prohibición de regreso" y el "principio de confianza. En: Estudios de derecho penal, Traducción de Peñaranda / Suárez / Cancio, Editorial Civitas, Madrid - España. 1997.

Injerencia y dominio del hecho. Estudios sobre la parte general del derecho penal. Reimpressão. Bogotá: Universidad Externado. 2004.

Acción y omisión en Derecho Penal. Bogotá: Universidad Externado. 2000.

JAPIASSÚ, Carlos Eduardo Adriano. O tribunal penal internacional. A internacionalização do Direito Penal. Rio de Janeiro: Lumen Juris, 2004.

JESCHECK, Hans-Heinrich; WEIGEND, Thomas. Tratado de Derecho Penal. Parte General. 2. ed. Granada: Comares. 2003. 
KAUFMANN, Dogmática de los delitos de omisión. 2. ed. Madrid: Marcial Pons. 2006.

LEITE, André Lamas. As posições de garantia na omissão impura. Em especial a questão da determinibilidade penal. Coimbra: Editora Coimbra, 2007.

LUZÓN PEÑA, Diego Manuel. Estudios penales, ed. PPU, Barcelona, 1991.

MARQUES, José Frederico. Tratado de direto penal. Campinas: Millenium, 2002.

MARTínEZ-BUjÁN PÉREZ, Carlos. Derecho Penal Económico. Parte General. Valencia: Tirantlo Blanch, 1998.

Derecho penal económico y de la empresa. Parte

General. Valencia: Tirant lo Blanch, 2007 Derecho Penal económico y de la empresa: Parte Especial. 4. ed. Valencia: Tirant lo Blanch. 2013.

El delito societario de administración fraudulenta. (Entre el delito patrimonial de la "infidelidad" y el delito societario del "abuso de facultades jurídico-sociales”), en EPCr, Proyecto de investigación Delitos económicos, dir. MARTíNEZBUJÁN PÉREZ, C., Universidad de la Coruña, vol. XVII, Santiago de Compostela, 1994.

Derecho penal económico y de la empresa, Parte Especial. Ed. Tirant lo Blanch, quinta edición, Valencia, 2015.

MAURACH, Reinhart. Tratado de Derecho Penal. Barcelona: Ariel. 1962.

MAYER, Derecho penal. Parte General, trad. Sergio Politoff, Buenos Aires, B de F, 2007.

MERKEL, Adolf. Derecho Penal: Parte general. Montevidéu, Buenos Aires: B de F. 2004.

MEZGER, Edmundo. Tratado de Derecho Penal. 3. ed., revista e atualizada. Madrid: Revista de Derecho Privado. 1957. 
MONTANER FERNÁNDEZ, Raquel. Gestión empresarial y atribución de responsabilidad penal. A propósito de la gestión medioambiental. Barcelona: Atelier, 2008.

MUNOZ CONDE, Francisco; GARCIA ARÁN, Mercedes. Derecho penal. Parte general. Valencia: Tiran lo Blach, 2007.

MUNHOZ NETTO, Alcides. Crimes Omissivos. Revista da Faculdade de Direito da Universidade Federal do Paraná, v. 20, ano 20, Curitiba: UFPR, 1980.

NUÑES CASTAÑO, Elena. Responsabilidad penal em la empresa. Valencia: Tirant lo Blanch, 2000.

ORTIZ, Mariana Tranchesi. Concurso de agentes nos delitos especiais. Dissertação de Mestrado apresentada à Faculdade de Direito da Universidade de São Paulo, 2010.

PASCHOAL, Janaína Conceição. Ingerência Indevida: os crimes comissivos por omissão e o controle pela punição do não fazer. Porto Alegre: SAFE, 2011.

PASTOR MUÑOZ, Nuria; COCA VILA, Ivó. El delito de administración desleal. Ed. Atelier, Barcelona, 2016.

PÉREZ CAPEDA, Ana Isabel. La responsabilidade de los Administradores de sociedade. Barcelona: Cedecs, 1997.

PRADO, Adriana. Zygmunt Bauman: "Vivemos tempos líquidos. Nada é para durar" (entrevista). Istoé entrevista- online. 24 de setembro de 2010.

PRADO. Luiz Régis. Curso de Direito Penal Brasileiro. Vol. 1, São Paulo: RT, 2011.

RADBRUCH, El concepto de acción y su importancia para el sistema del derecho penal. Buenos Aires: B de f, 2011. 
REALE JÚNIOR, Miguel. Dever de lealdade do administrador da empresa no Direito Penal. In: REALE, Miguel; REALE JÚNIOR, Miguel; REALE FERRARI, Eduardo (Orgs.). Experiências do direito. Campinas: Millenium, 2004.

ROXIN, Claus. Derecho Penal: Parte general. Tomo I. Trad. Diego-Manuel Luzón Peña; Miguel Díaz y García Colledo e Javier de Vicente Remesal. Madrid: Civitas, 2001.

Derecho Penal: Parte general. Tomo II - especiales formas de aparición del delito. Trad. Diego-Manuel Luzón Peña; José Manuel Paredes Castañon; Miguel Díaz y García Conlledo; e Jabier de Vicente Ramesal. Madrid: Civitas, 2014.

. Autoría y dominio del hecho en Derecho penal, traducción de Joaquín Cuello Contreras y José Luis Serrano Gonzáles de Murillo, Madrid, Marcial Pons, 2000.

Problemas Fundamentais do Direito Penal. 3. ed. Lisboa: Vega. 2004.

. Política criminal e sistema jurídico-penal. Renovar: Rio de Janeiro, Trad., Luís Greco, 2002.

. Novos estudos de Direito Penal. Org. Alaor Leite. São Paulo: Marcial Pons, 2014.

Estudos de Direito Penal. $2^{\text {a }}$ ed. Org. e trad. Luís Greco. Rio de Janeiro: Renovar, 2005.

Funcionalismo e imputação objetiva. Tradução dos $\S \S 7$ e 11, nm. 1/119 de Strafrecht, Allgemeiner Teil, 3.ed. München, Beck, 1997. Trad. e introdução Luís Greco. Rio de Janeiro/São Paulo: Renovar, 2002.

SALOMÃO FILHO, Calixto. Sociedade anônima: interesse público e privado. Revista de Direito Mercantil, Industrial, Econômico e Financeiro. São Paulo, v. 127, jul/set 2002.

SANTOS, Juarez Cirino dos. A moderna teoria do fato punível. 3. ed. rev. e ampl. - Curitiba: Fórum, 2004. 
SANTOS, Alexandre Pinheiro dos; OSÓRIO, Fábio Medina; WELLISCH, Julya Sotto Mayor. Mercado de Capitais - Regime Sancionador. São Paulo: Saraiva, 2012.

. Direito Penal: parte geral. Florianópolis: Conceito, 2012.

SCHÜNEMANN, Bernd. Consideraciones críticas sobre la situación espiritual de la ciencia jurídico-penal alemana. Trad. de Cancio Meliá, Bogotá, 1996.

Delincuencia empresarial: cuestiones dogmáticas y de política criminal. Buenos Aires: Fabián J. Di Plácidos, 2004.

EI Derecho en la globalización económica: imperialismo del líder y colonización de los órdenes jurídicos ¿Instrumentalización del Derecho Penal?, em Globalización e internacionalización del Derecho penal. Implicaciones político-criminales y Dogmáticas, Moisés Moreno (coordinador), Editora Ius Poenale, Cepolcrim, México, 2003.

Cuestiones básicas de dogmática jurídico penal y de política criminal acerca de la criminalidad de empresa, Anuario de Derecho Penal y Ciencias Penales, XLI. Madrid: Ministerio de Justicia, 1988.

Fundamentos y Limites de los Delitos de Omisión Impropia.

Madrid, Barcelona, Buenos Aires, São Paulo: Marcial Pons. 2009.

El Sistema Moderno del Derecho Penal: Cuestiones

Fundamentales, traducción de Silva Sánchez, Editorial Tecnos, Madrid - España, 1991.

La administración desleal de los órganos societarios: el caso Mannesmann, en La administración desleal de los órganos societarios, edits. GÓMEZ-JARA DÍEZ, C., GARCÍA CAVERO, P., Ed. ARA, Lima, 2010.

Los fundamentos de la responsabilidad de los órganos de dirección de empresas. Madrid, 2002. 
Sobre el estado actual de la dogmática de los delitos de omisión en Alemania, en Revista del Poder Judicial, 1998, tercer trimestre, tomo 51.

SILVA SÁNCHEZ, Jesús-María. A expansão do Direito Penal: aspectos da política criminal nas sociedades pós-industriais. Tradução Luiz Otavio de Oliveira Rocha. São Paulo: RT, 2002.

Responsabilidad penal de las empresas y de sus órganos en derecho penal. In: Libro-homenaje a Roxin. Barcelona: Bosch. 1995.

El Delito de Omisión: Concepto y Sistema. 2. ed. Buenos Aires, Montevidéu: B de F. 2003.

Criterios de asignación de responsabilidade em estructuras jerárquicas em Empresa y delito en el nuevo Código Penal. Dirigido por Enrique Bacialupo. Consejo General del Poder Judicial: Madri, 1997.

Aproximación ad Derecho Penal contemporáneo. Buenos Aires, Montevidéu: B de F. 2010.

Política Criminal en la dogmática: algunas cuestiones sobre su contenido y límites. En: Política Criminal y Nuevo Derecho Penal. Libro Homenaje a Claus Roxin, Editorial Bosch, Barcelona - España, 1997.

SILVEIRA, Renato de Mello Jorge. Direito Penal supra-individual: interesses difusos. São Paulo: Revista dos Tribunais, 2003.

SOUZA, Artur de Brito Gueiros. Preso estrangeiros no Brasil: aspectos jurídicos e criminológicos. Rio de Janeiro: Lumen Juns, 2007.

STRATENWERTH, Günter. Derecho Penal. Parte General. 4. ed., totalmente reelaborada. Buenos Aires: Hammurabi. 2005. 
TAVARES, Juarez. Teoria dos Crimes Omissivos. Madrid, Barcelona, Buenos Aires, São Paulo: Marcial Pons. 2012.

As Controvérsias em torno dos Crimes Omissivos. Rio de Janeiro: Instituto Latino-americano de Cooperação Penal, 1996.

Teoria do injusto penal. Belo horizonte: Del Rey, 2000.

TOLEDO, Francisco de Assis, Princípio Básicos de Direito Penal, São Paulo: Saraiva, 2002.

TIEDEMANN, Klaus. Derecho penal y nuevas formas de criminalidad. Trad. Manuel Abanto Vásquez. Lima: Grijley., 2007.

VON LISZT, Franz. Tratado de Direito Penal Alemão. Tomo I. Campinas: Russell. 2003.

ZÚÑIGA RODRÍGUEZ, Laura. Bases para un modelo de imputación de responsabilidad penal a las personas jurídicas. Navarra, Ed. Aranzadi, 2009.

Criminalidad de empresa, criminalidade organizada y modelos de imputación penal. In. Delincuencia organizada. Aspectos penales, procesales y criminológicos. Eds. Juan Carlos Ferré Olivé y Enrique Anarte Borallo. Huelva: Universidad de Huelva Publicaciones, 1999.

WELZEL, Hans. O novo sistema jurídico-penal. 2. a ed. Trad. Luiz Regis Prado. São Paulo: Revista dos Tribunais, 2009.

Derecho Penal Alemán: Parte General. Tradução da 11. ed. alemã. Santiago: Jurídica de Chile. 1976. 